incapable, when operated upon by motives, of passing through the successive changes preliminary to the state expressed by volition ; $2 \mathrm{~d}$, from incapacity to transmit its stimulus to the system of voluntary nerves. The general paralysis of insane people is an example of the first; hemiplegia, of the last. The system of voluntary motion has its laws, independent of the brain and of other agents; and while its excitability remains, it acts according to those laws, whether stimulated by the brain, by galvanism, or any irritant.

The argument for necessity by Collins, Edwards, and Locke, adapts itself happily to this view. That education increases the size, improves the powers and functional actions of the brain, few will deny. And it is universally admitted that the brain is the seat of the disease in mental derangement. The constant feature present in this disease, and the only constant one, is want of control. The meaning of which is, that there is a loss of balance between the effect of motives that excite to a given action and of ideas that suggest their consequences, and that joint effect of other motives tending to restrain the action of the first, and other ideas tending to modify the second, and enable us to judge of their truth if suggested by imagination, and of their present reality if suggested by memory. In all cases of excitement the former preponderate over the latter, producing exaggeration and perversion ; in imbecility, the latter, producing inconclusiveness, doubt, and hesitation. This, I believe, is susceptible of proof; and the only rational method of applying the two propositions together, viz. the organ deranged, and the features of derangement, and deducing a legitimate conclusion, is, to infer that these last arose from altered sensibility of the brain.

\title{
LARGE DOSES OF OPIUM IN RHEUMATISM.
}

[Communlcated for the Boston Medical and Surgical Journal.]

I stated, in a former communication to the Boston Medical and Surgical Journal, that when a proper opportunity presented itself, I would give an account of two more cases of rheumatism, in which large doses of opium were used. These were the first cases of rheumatic affection I ever saw. One patient, Mr. H. L., resided in E.; the other, D. S., Esq., in C. The former recovered, but the latter did not. H. L. was a young man, perhaps about twenty-five, of not a very robust constitution. He had been affected with moveable pains and swelled joints a week when I saw. Fever, rather of the typhoid type, had been seated upon him two or three days when I was first called. Thinking it "nothing but rheumatism," as they expressed themselves, they did not send for a physician as soon as they otherwise would have done. They would not have sent as soon as they did, had it not been for a profuse hæmorrhage from the nose, which they could not stop. My place of residence was six miles from his, and the hæmorrhage lasted from the time it commenced till after my arrival. It was suppressed by styptic applications externally and locally, and by pills of acetate of lead, opium 
and ipecacuanha internally. It was judged by those who were present that he lost four quarts of blood; but as blood shows more than it really is, this was probably an erroneous judgment. The treatment afterwards was the same as that of the other cases which $I$ have mentioned. This produced a mitigation of the pain and swelling, a gentle but continued diaphoresis, and the same sort of pleasurable sensations which were spoken of in my other communication. As the disorder had become so firmly seated, neither the pain, the swelling nor the fever could be entirely removed. Sometimes every joint was swollen, and sometimes only those of a particular limb. After commencing with the course above mentioned, he suffered not much if he kept still, but if he moved an inch without the greatest caution, the pain was excruciating.

In addition to the remedies prescribed for the rbeumatic affection, the fever, as may well be supposed, had to be looked to. This, as it was treated in the common way, need not be commented upon. For about a week he was as comfortable as could be expected, the effects of the treatment being pretty much what they were in the cases named in my other communication. The fever, however, somewhat increased, and from this cause, as I supposed, be was seized a second time with hæmorrhage from the nose. The loss of blood was great-so great, that I am unwilling to state what the opinion was in regard to it. Suffice it to say that it was suppressed as readily as in the former instance, and by the same remedies. I continued the opium course, but owing to the severe rheumatic affection, the fever and loss of blood, such a degree of subsultus tendinum presented itself, that every joint and every muscle was in motion. In the course of three weeks from the time I first saw him, the fever and swelling subsided, and the subsultus tendinum disappeared. Soon he began to talk of nourishment; and gruel, rice water and weak broths were allowed him. There had been a want of color in his face, but now, perhaps from the food that had been given him, there was a flush upon it. The fever, which had pretty much left him, again exhibited itself. His pulse were full and hard, and rbeumatic affection was again exhibiting itself in his joints. I was somewhat at a loss what to do, and was about to make a proposition for another physician to be called. His pulse being hard and full, 1 thought it would do no barm to bleed; I therefore took a pint from his arm, and from this time he continued to recover. His recovery, owing to bis debilitated state, was slow, but constant. From the healthful diaphoresis and other favorable effects of the medicine, there can be no doubt that the opium course was a useful one, and the only one which, aided by any other remedies, would have effected a cure. In regard to the hæmorrhage, it was the opinion of $\mathrm{Dr}$. W., an eninent physician in the district where $\mathrm{l}$ belonged, that he would not have recovered had it not been for this. "You would not have dared to bleed him," said be, "so much as his case required."

The case of D. S., Esq. was not deemed, at its commencement, so severe as the preceding. There was no hæmorrhage, and the fever was not so much of the typhoid type. The pain, swelling, redness and beat were equal to what they were in the other. I bled him twice, 
largely, and made use of the same treatment in addition to this, which has been mentioned in my account of the other cases. He was a person of a more robust and athletic constitution than the person of whom I have just spoken. Never, in any case, was there anything done that seemed to have a more favorable effect than this treatment. An abatement of the fever, subsidence of the swelling, pain and redness, diaphoresis, the softening and diminished frequency of the pulse, all promised very decidedly a favorable prognosis. His tongue was less coated, mouth moist, intestinal and urinary excretions regular, and every symptom favorable-much more so than in the case I have just treated of at the same period of the disease. He was weak and somewhat debilitated, to be sure, and on this account, Dr. R., of P., a physician considered by many to be very skilful in raising up, or "patching up," as he himself expressed it, weak patients, was proposed as a proper person to be sent for as a consulting physician. He had the reputation of being a regular physician, because he belonged to the Medical Society, but in practice he was more than half quack. One balf of the people believed in his superior medical attainments, and the other half believed him more conceited than learned, more confided in by people of an insufficiency of discernment, than worthy of confidence. He practised according to the Brunonian theory, and of course, as he patient was low and considered to be debilitated, he must have wine, bitters, and bark. These were administered, and in twenty-four hours the skin was dry and husky, the mouth was parched and furred, and the pulse were hard and wiry. In a week all the bad symptoms were so much aggravated, that it was deemed improper, even by Dr. R.'s admirers, to continue his course any longer. At my suggestion, Dr. W., the physician before referred to, was sent for. He had attained such eminence as a physician, that even Dr. R. had to quail under him. Rather than do this in the present instance, he declined coming any more. Dr. W. agreed with Dr. Armstrong in regard to depleting remedies, and of course thought it best to bleed. Generally his practice in regard to this was very judicious; but in the present case, on account of its having been resorted to at so late a period, I have always been fearful it did harm. This, as the inflaminatory symptoms when he first saw hirn were very high, he placed much dependence upon, and resorted to very extensively. He deemed it judicious, however, to keep up the opium course, and from this, though he did not recover, his sufferings were so alleviated, that he would never say that he experienced any pain. For the greatest part of the time while he was sick, if he moved carefully he was free from pain. Not only was he free from bodily suffering, but from mental likewise. He enjoyed himself, according to appearances, as well as though he had been in perfect health. On asking him how he did, he always said he was better, and would, in a good natured and pleasant way, say something to make you laugh. After the first few days, he never expressed any uneasiness of mind but once, and that was occasioned by the following circumstance. He was a candidate for office, and it being election day, thinking he might experience some solicitude about it, in allusion to it, I told hitn I supposed he would 
be as likely to obtain the election as though he was well. "I am sorry," said he, "you mentioned this. I have not felt so bad before since I was sick." He had now got to be pretty weak, and as I saw him afterwards shed tears and exhibit other symptoms of nervous excitement, I considered the sensorium somewhat affected. He died in four days afterwards, but never apparently suffered much either from bodily or mental pain, except in the instance alluded to. The advantages of opium can be perceived, even in these cases. In the first, I think it was so requisite as a medicine, that without it the patient never would have recovered. In the last, though it effected not a cure, it rendered the bed of death easy. Had it not been for the unphilosophical and unjustifiable practice of Dr. R., there cannot be much doubt that he would have got well.

It was mentioned in my other communication that one thing more would be mentioned in favor of this practice. Dr. W., of a neigbboring town, had practised, successfully, as he said, bathing in ice water for the rheumatism. I asked him in what way such a remedy could be successful. "By producing such a torpor of the ressels that were inflamed, that they could not recover tbemselves sufficiently to resume the inflammatory, or increased action. Bathing for a short time only, will not effect a cure. The inflammation would be ratber increased than relieved. By continuing it for a sufficient time, the heat and redness are first driven away, and afterwards the swelling and pain, and in one instance out of twenty they would scarcely be likely to recur." Though I considered this practice dangerous, I thought that opium, in connection with other remedies, might be used to such an extent, and be so long continued, as to operate in this way, and in most cases effect a cure without running the risk of doing harm.

Samuel Fish.

Boston, August 4, 1837.

BOSTON MEDICAL AND SURGICAL JOURNAL.

BOSTON, AUGUST 23,1837 .

\section{DISEASES OF NEW ORLEANS.}

From Dr. E. H. Barton's interesting address on acclimation, which has already been alluded to in the Journal, we take the following remarks on the diseases of New Orleans.

"Fortunately, our climate is subject to no great variety of diseases that are indigenous, when compared with other portions of our country, a large proportion of our complaints having other sources, many of the afflicted coming here for the benefit of climate. And if our acclimatement is sometimes severe, it is the only ordeal we have to pass through - no such immunity is enjoyed in the northern portions of the United States-no period of acclimation can protect the pulmonary organs of 